\title{
Persistent dilemmas in zoster eye disease
}

\author{
Elisabeth J Cohen, ${ }^{1}$ Jason Kessler ${ }^{2}$
}

${ }^{1}$ Department of

Ophthalmology, New York University School of Medicine, NYU Langone Medical Center, New York, New York, USA ${ }^{2}$ Department of Population Health, New York University School of Medicine, NYU Langone Medical Center, New York, New York, USA

\section{Correspondence to} Dr Elisabeth J Cohen, Department of Ophthalmology, New York University School of Medicine, NYU Langone Medical Center, MD, $33 \mathrm{E}$ 70th St. Apt. 6D, New York, NY 10021, USA; Elisabeth.cohen@nyumc.org

Received 28 January 2015 Revised 24 March 2015 Accepted 15 April 2015 Published Online First 12 May 2015

\section{ABSTRACT}

Herpes zoster ophthalmicus ( $\mathrm{HZO}$ ) is a common, vision and potentially life-threatening disease caused by the reactivation of the varicella-zoster virus (VZV) in the distribution of the first division of cranial nerve

V. Although the rate of herpes zoster increases with age, over half of the people with zoster in general, including $\mathrm{HZO}$, are under age 60 . In addition, over $90 \%$ of people with zoster are immunocompetent, even though the disease is more common and severe in immunocompromised patients. The incidence of zoster is increasing worldwide for unknown reasons. The epidemiology has not yet been impacted by the zoster vaccine $(\mathrm{ZV})$. The lack of a strong recommendation by physicians for this vaccine is a major barrier to its use. An unresolved dilemma regards the optimum timing for this vaccine. In the USA, the current recommendation by the Centers for Disease Control and Prevention (CDC) is for eligible people age 60 and older, despite its greater efficacy in reducing the incidence of disease and Food and Drug Administration (FDA) approval for age 50-59. Although there is a consensus regarding use of acute high-dose oral antiviral treatment to reduce ocular complications, there is limited evidence for prolonged treatment. The rationale for a proposed randomised controlled trial (RCT) of suppressive antiviral treatment to reduce chronic eye disease and postherpetic neuralgia (PHN) includes evidence that zoster is followed by chronic active VZV infection and similarities between HZO and herpes simplex virus (HSV) eye infection, where this treatment is effective and is the standard of care.

\section{INTRODUCTION}

Herpes zoster (HZ), also referred to as shingles, is caused by reactivation of the varicella-zoster virus (VZV) in people who have had chickenpox (varicella), the primary infection caused by VZV, typically resulting in a painful, unilateral, dermatomal, vesicular rash (figure 1). There are about one million new cases of HZ in the USA annually, of which up to $20 \%$ involve the first division of cranial nerve $\mathrm{V}$ (trigeminal) resulting in herpes zoster ophthalmicus (HZO). HZ affects approximately $30 \%$ of the population, increasing to $50 \%$ of people who live beyond age 85 years. ${ }^{1}$

It is a common misconception that $\mathrm{HZ}$ is a disease of the elderly. Although the rate of $\mathrm{HZ}$ increases with age, the number of cases in general, including $\mathrm{HZO}$, peaks in individuals age $50-79 .^{2-4}$ The mean age of onset in the USA is approximately 52 years. ${ }^{5}$ That more than half of all cases of $\mathrm{HZ}$ occur in people under age 60 is not a new phenomenon, as $58 \%$ of patients were less than 60 in a paper published in $1971 .^{6}$ Although postherpetic neuralgia (PHN), defined as chronic, often incapacitating, dermatomal pain persisting more than 90 days, affects primarily people with $\mathrm{HZ}$ onset age 60 years and older, younger-onset patients suffer from acute pain with a mean duration of approximately 1 month, and are at risk for other complications, including, but not limited to, visionthreatening chronic eye disease.

The incidence of $\mathrm{HZ}$ has been steadily increasing in the USA since the year 2000 among people age 40 and older for unknown reasons. ${ }^{8}$ The incidence of HZ in North America, Europe and the Asia Pacific is comparable and increasing, and this trend started in the absence of varicella vaccination programmes against chickenpox. ${ }^{9}$ In developed countries, the age-adjusted rates of $\mathrm{HZ}$ are similar, and even higher in regions of the world with widespread HIV infection. ${ }^{9} 10$

Another common misconception is that healthy people are not at risk for $\mathrm{HZ}$. Although $\mathrm{HZ}$ is more common and severe in immunocompromised people, 92\% of people with $\mathrm{HZ}$ are not immunocompromised. ${ }^{4}$ Relatively young and healthy patients with zoster can develop serious sequelae, including neurological complications and probably coronary artery disease in addition to eye disease. ${ }^{11-13}$

A retrospective population-based cohort study in Hawaii found the incidence of HZO was 30.9 per 100000 patient years. ${ }^{14}$ The incidence was highest in people age 65 and older (104.6 per 100000 patients, compared with 42.2 in ages 45-64, 15.4 in ages 25-44 and 7.2 in ages 15-24), but similar numbers of cases occurred in people ages 45-64 (54 cases) and ages 65 and older (56 cases). Ocular involvement occurred in $35.1 \%$ of patients with $\mathrm{HZO}$, with keratitis being the most common manifestation. Overall, PHN developed in 20.9\% of patients, but occurred in $30 \%$ of patients with ocular involvement in comparison to $16 \%$ with only skin involvement $(p=0.08)$. Patients age 65 and older were significantly more likely to have PHN than younger patients $(p=0.009)$.

$\mathrm{HZ}$ can result in chronic pain, diminished quality of life, chronic eye disease, reduced vision and even death. ${ }^{15}$ Most studies find that women are affected significantly more frequently than men with regard to $\mathrm{HZ}$ incidence, hospitalisations and mortality. ${ }^{14} 17 \quad 18$ PHN persists for longer than 1 year in nearly half of the patients older than age $70 .{ }^{19-21}$ The direct medical cost burden of $\mathrm{HZ}$ may exceed US $\$ 1$ billion annually in the USA. ${ }^{20}$ In patients with HZ who develop PHN, 1-year costs are more than five times greater than costs in patients with $\mathrm{HZ}$ without PHN. ${ }^{19}$ The negative impact of $\mathrm{HZ}$ and PHN on health-related quality of life is closely correlated with the severity of pain and persists as long as clinically significant pain. ${ }^{72}$ A population-based study shows that $\mathrm{HZ}$ is a risk factor for developing major depression. ${ }^{23}$ Notably, PHN has been reported to be the most common cause of suicide in chronic pain patients who are over age $70 .^{24}$ 


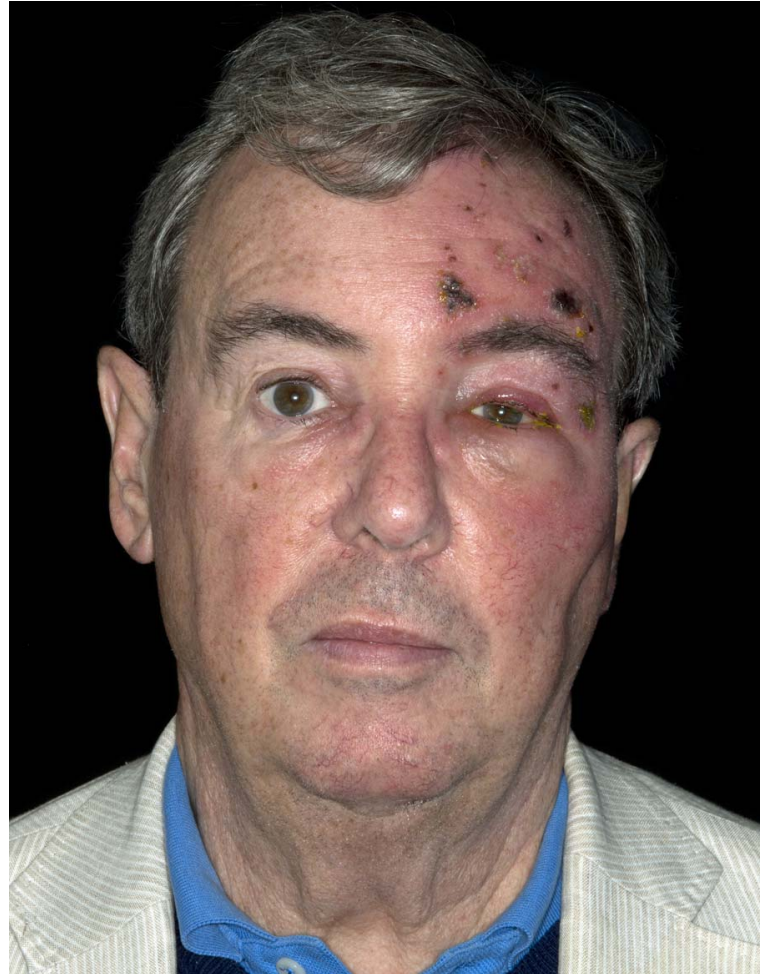

Figure 1 View of the face of a 70-year-old man during an attack of shingles, also known as herpes zoster. A red rash with blisters has appeared on his forehead, and his eye is swollen. This rash is extremely painful and is due to herpes infecting the sensory nerves, in this case the ophthalmic branch of the trigeminal nerve. Shingles is caused by the chickenpox virus (varicella-zoster). Dormant viruses survive for years in humans until the immune system is weakened by illness or age. Credit: Dr P. Marazzi, Science Photo Library.

Publications that compare $\mathrm{HZO}$ with $\mathrm{HZ}$ occurring in other locations point to the risk of $\mathrm{PHN}$ and stroke being greater after $\mathrm{HZO}$ than $\mathrm{HZ}$ elsewhere. ${ }^{22} 25$ PHN after HZO lasts longer and is more frequent than PHN after $\mathrm{HZ}$ in general, despite recommended acute antiviral treatment. ${ }^{21} 2225$ Although potentially fatal strokes are an uncommon complication of $\mathrm{HZ}$, patients with HZO have 4.5 times higher risk of stroke within a year after diagnosis compared with controls, and the adjusted HR of stroke after $\mathrm{HZO}$ is 4.3 compared with 1.3 after $\mathrm{HZ}$ in general. $^{26} 27$ In a self-controlled, case-series, population-based study, the risk of stroke for 6 months more than doubled after $\mathrm{HZO}$ compared with $\mathrm{HZ}$ in general. ${ }^{28}$ Although the risk of stroke after $\mathrm{HZ}$ is greatest in the short term, increased risk continues beyond the first year, and is greatest in patients under age $40 . .^{29}$

Disease manifestations of $\mathrm{HZO}$ vary with the age at onset of disease. In a retrospective study of over 100 patients with HZO, in which half of the cases had an onset under age 60 years, late dendriform keratitis occurred more often in patients who were under age 60 compared with those age 60 or older $(36 \%$ vs $17 \%, \mathrm{p}=0.03)^{3}$ (figures $2 \mathrm{~A}, \mathrm{~B}$ ). Younger patients averaged 3.2 episodes of recurrent inflammation, compared with older patients with 1.5 episodes $(p=0.01)$. Complications, including PHN, neurotrophic keratitis and secondary infected corneal ulcers, were all significantly more common in older-onset patients $38 \%$ for those age 60 or older at onset vs $8 \%$ for those under age 60 at onset, $\mathrm{p}=0.001 ; 31 \%$ vs $9 \%, \mathrm{p}=0.005$ and $17 \%$ vs $3 \%, \mathrm{p}=0.04$; respectively).
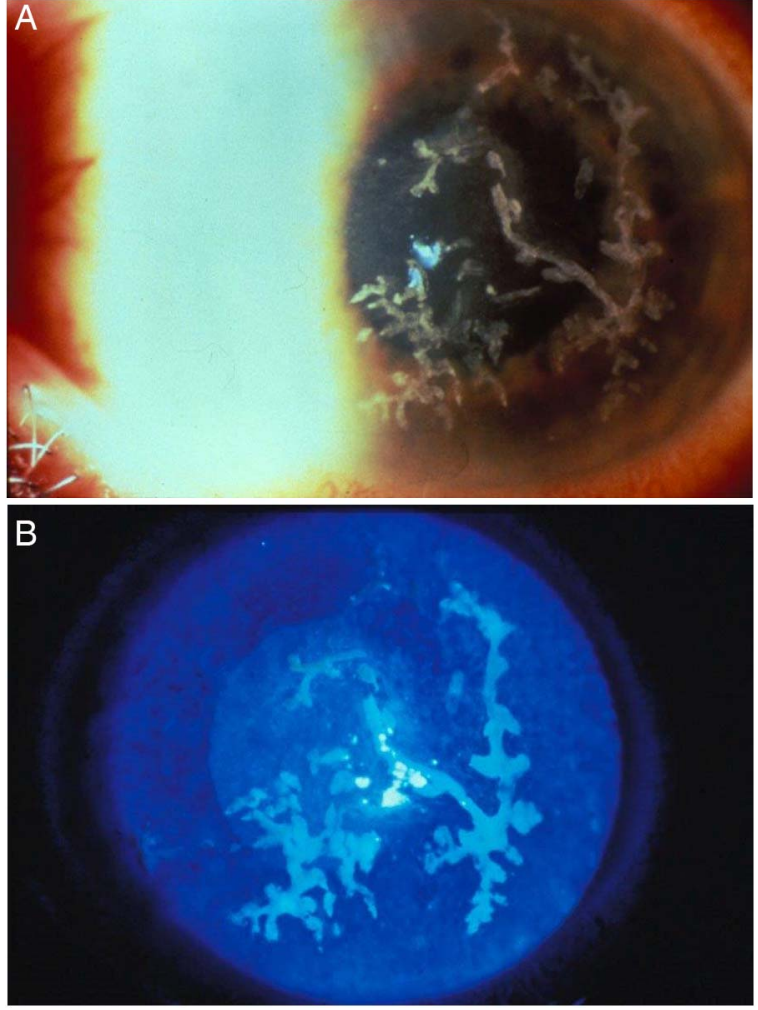

Figure 2 (A) Typical late dendriform keratitis due to varicella-zoster virus (VZV). These branching elevated lesions without terminal bulbs are often PCR-positive for VZV and respond to topical gangciclovir, evidence that they are signs of chronic and/or recurrent VZV infection. (B) The dendriform lesions stain with fluorescein.

\section{THE ZOSTER VACCINE}

The zoster vaccine (ZV) (Zostavax (Zoster Vaccine Live), Merck $\&$ Co., Whitehorse Station, New Jersey, USA) is recommended by Centers for Disease Control and Prevention (CDC) for immunocompetent patients age 60 and older since 2006 in the USA, and was approved by the Food and Drug Administration (FDA) for immunocompetent patients age 50 and older in 2011. ${ }^{30} 31$ This vaccine is a live vaccine using the attenuated Oka strain of VZV at $14 \times$ the concentration used in the varicella vaccine. In the USA, it costs between US\$185 and US\$230. This vaccine decreases the incidence of $\mathrm{HZ}$ by approximately $50 \%,{ }^{30}$ but it has failed yet to affect the epidemiology of zoster. ${ }^{10}$ As of 2013, according to CDC, it had been received by only approximately $24 \%$ of eligible individuals in the USA age 60 and older. Given that the mean age of onset in the USA is approximately 50, and the vaccine reduces the incidence by only $50 \%$, over $95 \%$ of all people in the USA are at continued risk for $\mathrm{HZ}^{5}{ }^{32}$

\section{Vaccine efficacy and safety}

In a randomised controlled trial (RCT) of over 38000 people age 60 years and above, the ZV reduced the burden of disease (a combination of incidence, severity and duration) by $61.1 \%$, PHN by $66.5 \%$ and the incidence of $\mathrm{HZ}$ by $53.1 \%$. $^{30}$ The incidence of $\mathrm{HZ}$ was reduced by $63.9 \%$ in people age $60-69$ and only $37.6 \%$ in people age 70 years and older. Because the effect on severity of disease was greater among older patients, the reduction in burden of disease was similar in both age groups. ${ }^{30}$ After a subsequent study reported a $68 \%$ reduction in incidence of $\mathrm{HZ}$ following the $\mathrm{ZV}$ in people age 50-59, the FDA 
approved the vaccine for this age group. ${ }^{33}$ Immunocompromise, due to diseases or treatment, reducing T-cell-mediated immunity, is the main contraindication for this live vaccine (http:/ www.cdc.gov/vaccines).

The vaccine is safe, with only local injection site reactions and headaches $(6 \%)$ occurring more often in vaccine recipients than in controls. ${ }^{31}$ Local reactions are significantly more common in younger than in older people. ${ }^{30} 3435$ These reactions may reflect the greater immune response of younger vaccine recipients.

There are case reports of two patients with HZO who developed recurrences 3 and 5 weeks after ZV, respectively, likely due to an immune response. ${ }^{36} 37$ Patients with $\mathrm{HZO}$ should be informed of this, and monitored 3-6 weeks after ZV.

Two cases of acute retinal necrosis 6 days and 2 months after the $\mathrm{ZV}$, respectively, raise safety issues. ${ }^{38}$ The $\mathrm{ZV}$ was contraindicated in one renal transplant patient. The other patient had end-stage renal disease, which was associated with lymphoid immune dysfunction, but not a current CDC contraindication. ${ }^{39}$ The contraindication for $\mathrm{ZV}$ in people with impaired cellular immunity should be strictly followed.

\section{Overcoming barriers to vaccination}

Barriers to use of the ZV in the USA include high cost, complex and partial reimbursement, frozen storage requirement and lack of a strong recommendation by primary-care doctors. ${ }^{40} 41$ Despite interventions to overcome these barriers, including education, availability at pharmacies and electronic medical record reminders, primary-care doctors do not consider this vaccine as important as influenza and pneumonia vaccines. ${ }^{42} 43$ Ophthalmologists can also recommend this vaccine to their patients. ${ }^{41}$ Implementation of evidence-based medical practices requires changes first in knowledge, then attitudes and finally practice. ${ }^{44}$ According to the bioethicist, Arthur Caplan, changes in behaviour also involve a sense of moral obligation to do the right thing (personal communication).

\section{Timing of vaccination}

Despite $68 \%$ efficacy in preventing $\mathrm{HZ}$ in people vaccinated age 50-59, FDA approval of ZV for this age group in 2011 and an absence of supply issues since 2012, as of 2014, the CDC continues to recommend this vaccine only for people age 60 years and older. ${ }^{45}$ They base this decision in part on the analysis of a recent decision (cost-effectiveness) model that demonstrates lesser health impacts and a higher incremental cost-effectiveness ratio (ie, dollars per unit of health gained) of vaccination at age 50 as compared with vaccination at older ages. ${ }^{46}$ In contrast, a previous modelling study based on UK data estimated that vaccination for $\mathrm{HZ}$ for those between 50 and 59 would be costeffective. ${ }^{47}$ The results of the CDC analysis were likely strongly influenced by uncertainty of data regarding vaccine durability, complication rates and impact of $\mathrm{HZ}$ and $\mathrm{PHN}$ and costs. ${ }^{48}$ New insights into these uncertainties may alter the attractiveness of ZV among younger cohorts.

Data on people vaccinated age 60 years and older in the short-term persistence study and the long-term persistence study indicate that efficacy of the vaccine wanes after 8 years for incidence of disease and 10 years for burden of illness and PHN. ${ }^{49}{ }^{50}$ No long-term efficacy studies have been done on people vaccinated at age 50-59, who may have a differential durability of response (ie, a patient vaccinated at younger age may maintain a greater degree of protection over a given time period than the same patient vaccinated at an older age).$^{51}$ Furthermore, recent evidence supports that there are similar immunological responses in those undergoing revaccination as compared with first-time vaccinees, suggesting that revaccination after initial vaccine efficacy wanes is scientifically plausible. ${ }^{52}$

The incidence of complications in the CDC study is based on a single publication regarding one county in Minnesota, ${ }^{4}$ which may not be representative of the US population, and non-PHN complications of $\mathrm{HZ}$ may have been underestimated. ${ }^{46}$ Recent epidemiological and biological evidence links incident HZ (and especially HZO) with ischaemic stroke, ${ }^{26-29}$ a highly morbid disease with large healthcare costs. There is evidence to suggest that the risk of stroke following $\mathrm{HZ}$ (or HZO) is greatest among younger people ( $<60$ years), ${ }^{29}$ potentially increasing the value of prevention among this population. Furthermore, recurrence of $\mathrm{HZ}$ may be more prevalent than initially suspected, ${ }^{53}$ which was not accounted for in the CDC analysis. Substantial recurrence rates among patients under 60 years of age could further increase the indirect and productivity costs incurred by this population, which is not accounted for in the CDC costeffectiveness calculations.

Methods of accounting for both direct (eg, vaccine-related costs, healthcare usage) and indirect costs (eg, lost time at work) may have increased the inefficiency of earlier vaccination strategies. Inclusion of costs related to minor local reactions (greater incidence in 50-59 vaccine recipients) and non-inclusion of productivity losses (also greater in patients with $\mathrm{HZ}$ age $50-59)^{20}$ could act in concert to make earlier vaccination appear less valuable in this analysis.

Clearly, more research is needed to address key questions related to the durability of response to $\mathrm{ZV}$, and the potential for revaccination, in order to clarify the most optimal prevention strategies, since $\mathrm{ZV}$ is more effective in preventing $\mathrm{HZ}$ in younger recipients.
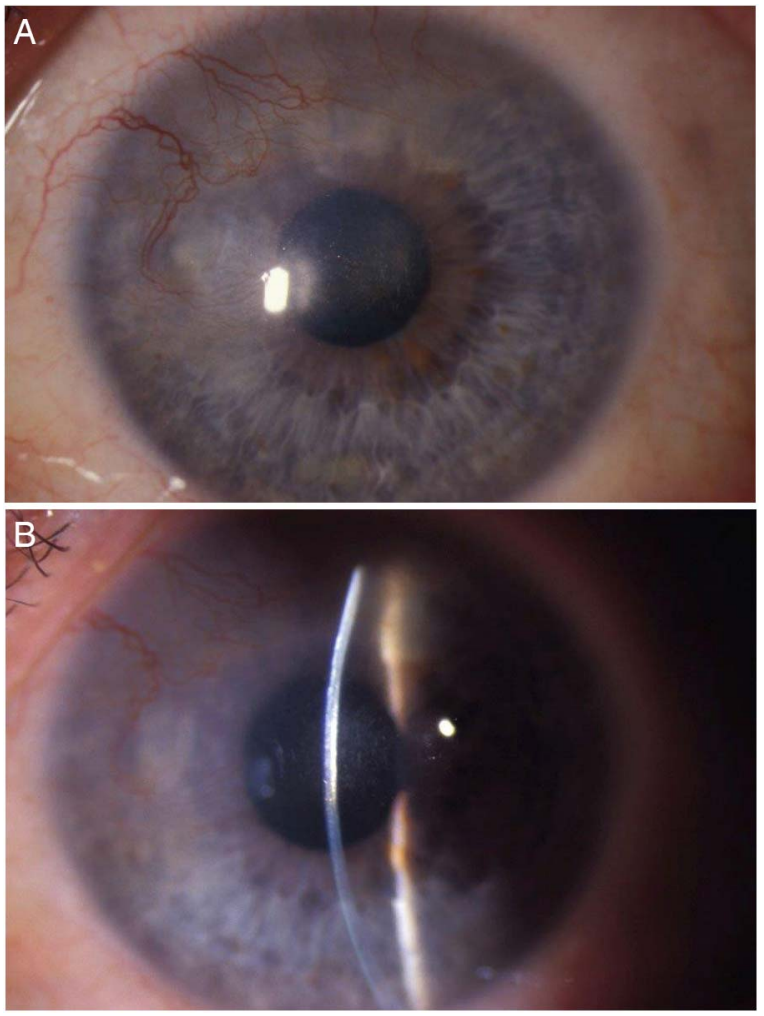

Figure 3 Stromal keratitis without ulceration. (A). Broad slit-lamp image with corneal neovascularisation and stromal opacity with lipid deposition. (B). Narrow slit image showing stromal keratitis. 


\section{RATIONALE FOR INVESTIGATION OF SUPPRESSIVE ANTIVIRAL TREATMENT IN HZO}

Although there is considerable consensus on oral antiviral treatment of acute $\mathrm{HZO}$, there is no standard approach to treatment of HZO sequelae, including ocular disease and PHN. Standard recommended care, consisting of acute oral antiviral treatment beginning within $72 \mathrm{~h}$ of rash onset with valacyclovir $1000 \mathrm{mg}$ three times daily, famciclovir $500 \mathrm{mg}$ three times daily or acyclovir $800 \mathrm{mg}$ five times daily for 1 week reduces chronic ocular complications from $50 \%$ to $30 \%$, but does not prevent them $^{54} 55$ or reduce PHN. ${ }^{56} 57$ Long-term topical corticosteroids are needed to control stromal keratitis, endothelialitis and/ or uveitis in most patients with chronic HZO disease (figures 2, $3 \mathrm{~A}, \mathrm{~B}, 4$ and 5). Effective treatment for dendriform keratitis is topical gangciclovir five times a day for 2 weeks and then twice daily for 2-4 weeks. ${ }^{58}$ Use of long-term suppressive oral antivirals is highly variable. ${ }^{59}$

Several factors call for evaluating long-term suppressive antivirals to prevent HZO complications in an RCT: recent discoveries about the infectious pathogenesis of complications of $\mathrm{HZ}$ and $\mathrm{HZO}$, the significant benefit of suppressive antivirals in reducing recurrent herpes simplex virus (HSV) stromal keratitis and evidence of comparable benefit of suppressive antiviral treatment of chronic $\mathrm{HZO}$ and $\mathrm{HSV}$ in a retrospective study. $^{60-63}$ A 2012 editorial in Archives of Ophthalmology suggested that ' $\ldots$ although stromal keratitis or uveitis may not represent active viral infection, clinicians may question whether subclinical or intermittent viral shedding may help to perpetuate destructive, inflammatory, anterior segment disease in HZO'. ${ }^{64}$ In one survey, over $85 \%$ of specialists reported treating cases of chronic or recurrent $\mathrm{HZO}$ in the preceding year. They reported prescribing oral antivirals most often for 7-14 days (37\%), while some used them for a year or longer $(15 \%)$ and others as long as patients were on topical corticosteroids (15\%). ${ }^{59}$ Confirming that long-term antiviral treatment reduces morbidity associated with chronic HZO could significantly reduce the disease burden for patients and costs to society.

\section{Evidence of chronic active VZV infection after HZ and HZO}

The rationale for a randomised placebo-controlled trial of prolonged suppressive valacyclovir treatment of $\mathrm{HZO}$ includes the increasing body of evidence that chronic active VZV infection occurs after $\mathrm{HZ}$ and contributes to complications, including dendriform keratitis, uveitis, PHN and strokes. ${ }^{61} 62$ 65-69 In 1995, a study showed that late epithelial dendriform keratitis lesions were often PCR-positive for VZV, and this was confirmed in 2010 by a larger series. ${ }^{61}{ }^{62}$ Dendriform keratitis'

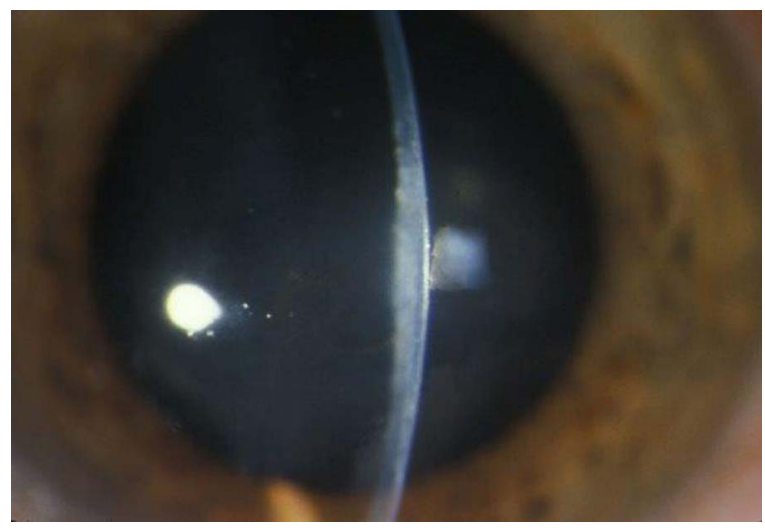

Figure 4 Endothelial keratitis with localised full-thickness corneal oedema.

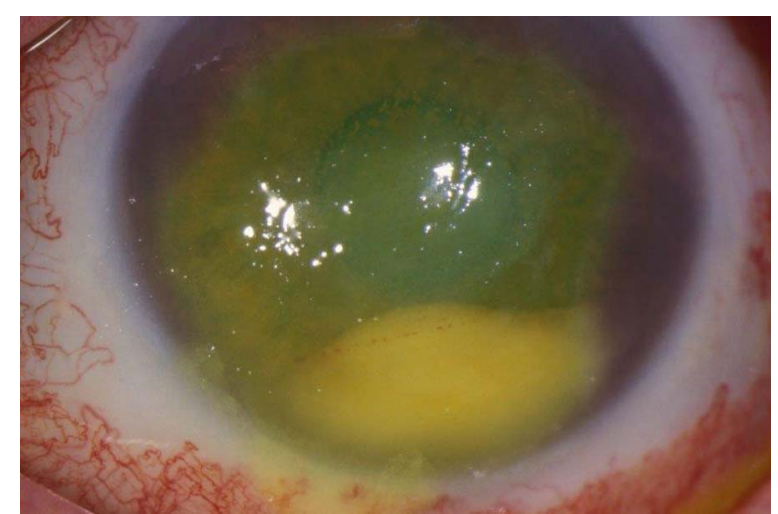

Figure 5 Case of zoster sine herpete (radicular pain without rash) associated with neurotrophic keratitis, uveitis with hypopyon and necrotising scleritis. After epithelial defect heals, uveitis is treated with topical steroids. Scleritis requires systemic treatment.

response to antiviral treatment is further evidence that it is caused by active VZV infection. ${ }^{58} 62 \mathrm{VZV}$ DNA has been found to persist in the saliva of $67 \%(21 / 32)$ of people with a past history of $\mathrm{HZ}$ up to 12 years after disease onset, ${ }^{70}$ but not in the saliva of healthy people. ${ }^{71}$

The finding of VZV DNA in blood mononuclear cells of patients who have $\mathrm{HZ}$ with $\mathrm{PHN}$, in the arteries of patients with zoster-related strokes and, most recently, in temporal arteries of patients with possible and proven giant cell arteritis is helping to raise awareness of the devastating consequences of chronic active VZV infection and the potential for improved antiviral treatment of these conditions. ${ }^{72-74}$

In 2014, HZ was reported as a risk factor for myocardial infarction in addition to cerebrovascular disease. ${ }^{11-13}$ An editorial concludes, 'The growing awareness of the role of VZV in vascular disease promises to lead to clinical trials to assess the benefit of antiviral therapy'. ${ }^{75}$

\section{Herpetic eye disease study: oral antivirals to reduce recurrent ocular HSV disease}

The herpetic eye disease study (HEDS) acyclovir prevention trial (APT) examined long-term use of oral acyclovir to prevent recurrent HSV disease, and found a $45 \%$ reduction $(95 \% \mathrm{CI}$ 0.41 to $0.75, \mathrm{p}<0.001)$ in recurrent ocular disease over 1 year. ${ }^{63}$ On the basis of this landmark study, recommended care for HSV eye disease changed to include prolonged suppressive antiviral treatment. In HEDS APT, suppressive antiviral treatment for 1 year was most beneficial in preventing recurrence of stromal keratitis, reducing it from $28 \%$ to $14 \%$ (95\% CI 0.29 to $0.80, \mathrm{p}=0.005) .{ }^{63}$ A retrospective community-based cohort study also concluded that patients were significantly less likely to have recurrent HSV epithelial keratitis and stromal keratitis on prolonged suppressive treatment. ${ }^{76}$ There is an absence of direct evidence that viral replication contributes to either $\mathrm{HZO}$ or HSV stromal keratitis.

A retrospective study reported efficacy of suppressive antiviral treatment in both HSV and HZO disease. Immune status of patients was not reported. This study found that in patients with $\mathrm{HZO}$, this treatment reduced the overall number of recurrences to 2.1 per year, compared with 3.4 episodes without antiviral treatment, a $35 \%$ reduction $(\mathrm{p}<0.05) .{ }^{60}$ The same treatment of patients with HSV keratitis reduced recurrences to 2.3 from 3.8 , a $39 \%$ reduction $(\mathrm{p}<0.05)$. In both $\mathrm{HZO}$ and HSV, stromal keratitis and/or uveitis were the most common forms of recurrent disease. 


\section{Zoster eye disease study}

The proposed zoster eye disease study (ZEDS) is analogous to the HEDS APT design. If funded by the National Eye Institute in the USA, study participants in the USA will be randomised in a double-masked, placebo-controlled trial to 1 year of oral valacyclovir $1000 \mathrm{mg}$ daily or placebo, with follow-up every 3 months for a total of 18 months, to compare the rates of new or worsening anterior segment ocular disease during and after treatment. Valacyclovir, a prodrug of acyclovir, achieves a higher serum level of acyclovir, which is necessary due to the higher inhibitory concentration of VZV compared with $\mathrm{HSV}^{77}$ Efficacy regarding incidence, severity and duration of PHN during and following treatment will also be assessed. Concluding as a result of this trial that valacyclovir is effective as suppressive treatment in patients with HZO in reducing ocular disease and/or PHN would be a major advance in management of $\mathrm{HZO}$ and possibly $\mathrm{HZ}$ in other locations.

Contributors The authors have contributed to and take responsibility for the content of the review article.

Competing interests None declared.

Provenance and peer review Commissioned; externally peer reviewed.

\section{REFERENCES}

1 Liesegang TJ. Herpes zoster ophthalmicus natural history, risk factors, clinical presentation, and morbidity. Ophthalmology 2008;115(2 Suppl):S3-12.

2 Insinga RP, Itzler RF, Pellissier JM, et al. The incidence of herpes zoster in a United States administrative database. J Gen Intern Med 2005;20:748-53.

3 Ghaznawi N, Virdi A, Dayan A, et al. Herpes zoster ophthalmicus: comparison of disease in patients 60 years and older versus younger than 60 years. Ophthalmology 2011;118:2242-50.

4 Yawn BP, Saddier P, Wollan P, et al. A population-based study of the incidence and complication rates of herpes zoster before zoster vaccine introduction. Mayo Clin Proc 2007;82:1341-9.

5 Hernandez PO, Javed S, Mendoza N, et al. Family history and herpes zoster risk in the era of shingles vaccination. J Clin Virol 2011:52:344-8.

6 Rogers R, Tindall J. Geriatric herpes zoster. J Am Geriatr Soc 1971;19:495-504.

7 Drolet $\mathrm{M}$, Brisson M, Schmader KE, et al. The impact of herpes zoster and postherpetic neuralgia on health-related quality of life: a prospective study. CMAJ 2010;182:1731-6.

8 Rimland D, Moanna A. Increasing incidence of herpes zoster among veterans. Clin Infect Dis 2010;50:1000-5.

9 Kawai K, Gebremeskel BG, Acosta CJ. Systematic review of incidence and complications of herpes zoster: towards a global perspective. BMJ Open 2014;4: e004833.

10 Yawn BP, Gilden D. The global epidemiology of herpes zoster. Neurology 2013:81:928-30.

11 Breuer J, Pacou M, Gauthier A, et al. Herpes zoster as a risk factor for stroke and TIA: a retrospective cohort study in the UK. Neurology 2014;82:206-12.

12 Wang CC, Lin CL, Chang YJ, et al. Herpes zoster infection associated with acute coronary syndrome: a population-based retrospective cohort study. $\mathrm{Br}$ I Dermatol 2014:170:1122-9.

13 Wu PY, Lin CL, Sung FC, et al. Increased risk of cardiovascular events in patients with herpes zoster: a population-based study. J Med Virol 2014;86:772-7.

14 Borkar DS, Tham VM, Esterberg E, et al. Incidence of herpes zoster ophthalmicus: results from the Pacific Ocular Inflammation Study. Ophthalmology 2013;120:451-6.

15 Johnson RW, Bouhassira D, Kassianos G, et al. The impact of herpes zoster and post-herpetic neuralgia on quality-of-life. BMC Med 2010;8:37.

16 Johnson RW, Rice AS. Clinical practice. Postherpetic neuralgia. N Engl J Med 2014;371:1526-33.

17 Ultsch B, Siedler A, Rieck T, et al. Herpes zoster in Germany: quantifying the burden of disease. BMC Infect Dis 2011;11:173.

18 Studahl M, Petzold M, Cassel T. Disease burden of herpes zoster in Swedenpredominance in the elderly and in women - a register based study. BMC Infect Dis 2013;13:586.

19 Ultsch B, Köster I, Reinhold T, et al. Epidemiology and cost of herpes zoster and postherpetic neuralgia in Germany. Eur J Health Econ 2013;14:1015-26.

20 White RR, Lenhart G, Singhal PK, et al. Incremental 1-year medical resource utilization and costs for patients with herpes zoster from a set of US health plans. Pharmacoeconomics 2009:27:781-92.

21 De Moragas JM, Kierland RR. The outcome of patients with herpes zoster AMA Arch Derm 1957;75:193-6.
22 Bouhassira D, Chassany O, Gaillat J, et al. Patient perspective on herpes zoster and its complications: an observational prospective study in patients aged over 50 years in general practice. Pain 2012;153:342-9.

23 Chen MH, Wei HT, Su TP, et al. Risk of depressive disorder among patients with herpes zoster: a nationwide population-based prospective study. Psychosom Med 2014;76:285-91.

24 Hess TM, Lutz LJ, Nauss LA, et al. Treatment of acute herpetic neuralgia. A case report and review of the literature. Minn Med 1990;73:37-40.

25 Volpi A, Gatti A, Pica F, et al. Clinical and psychosocial correlates of post-herpetic neuralgia. J Med Virol 2008:80:1646-52.

26 Lin HC, Chien CW, Ho JD. Herpes zoster ophthalmicus and the risk of stroke: a population-based follow-up study. Neurology 2010;74:792-7.

27 Kang JH, Ho JD, Chen YH, et al. Increased risk of stroke after a herpes zoster attack: a population-based follow-up study. Stroke 2009;40:3443-8.

28 Langan SM, Minassian C, Smeeth L, et al. Risk of stroke following herpes zoster: a self-controlled case-series study. Clin Infect Dis 2014;58:1497-503.

29 Sreenivasan N, Basit S, Wohlfahrt J, et al. The short- and long-term risk of stroke after herpes zoster-a nationwide population-based cohort study. PLOS ONE 2013;8:e69156.

30 Oxman MN, Levin MJ, Johnson GR, et al. A vaccine to prevent herpes zoster and postherpetic neuralgia in older adults. N Engl J Med 2005;352:2271-84.

31 Harpaz R, Ortega-Sanchez IR, Seward JF, et al. Prevention of herpes zoster: recommendations of the Advisory Committee on Immunization Practices (ACIP). MMWR Recomm Rep 2008;57(RR-5):1-30; quiz CE2-4.

32 Centers for Disease Control and Prevention. MMWR News Synopsis for 5 February 2015. http://www.cdc.gov/media/mmwrnews/2015/0205.html (accessed on $10 \mathrm{Mar}$ 2015).

33 Schmader $\mathrm{K}$, Levin $\mathrm{M}$, Gnann JJ, et al. Efficacy, safety, and tolerability of herpes zoster vaccine in persons aged 50-59 years. Clin Infect Dis 2012;54:922-8.

34 Tyring S, Diaz-Mitoma F, Padget L, et al. Safety and tolerability of a high-potency zoster vaccine in adults $>l=50$ or years of age. Vaccine 2007;25:1877-83.

35 Tseng H, Liu A, Sy L, et al. Safety of zoster vaccine in adults from a large managed-care cohort: a Vaccine Safety Datalink study. J Intern Med 2012;271:510-20.

36 Sham CW, Levinson RD. Uveitis exacerbation after varicella-zoster vaccination in an adult. Arch Ophthalmol 2012;130:793-4.

37 Khalifa YM, Jacoby RM, Margolis TP. Exacerbation of zoster interstitial keratitis after zoster vaccination in an adult. Arch Ophthalmol 2010;128:1079-80.

38 Charkoudian LD, Kaiser GM, Steinmetz RL, et al. Acute retinal necrosis after herpes zoster vaccination. Arch Ophthalmol 2011;129:1495-7.

39 Betjes MG. Immune cell dysfunction and inflammation in end-stage renal disease. Nat Rev Nephrol 2013;9:255-65.

40 Hurley $L$, Lindley $M$, Harpaz $R$, et al. Barriers to the use of herpes zoster vaccine. Ann Intern Med 2010;152:555-60.

41 Jung J, Elkin Z, Li X, et al. Increasing use of the vaccine against zoster through recommendation and administration by ophthalmologists at a city hospital. Am J Ophthalmol 2013;155:787-95.

42 Elkin Z, Cohen E, Goldberg J, et al. Studying physician knowledge, attitudes, and practices regarding the herpes zoster vaccine to address perceived barriers to vaccination. Cornea 2013;32:976-81.

43 Elkin Z, Cohen E, Goldberg J, et al. Improving adherence to national recommendations for zoster vaccination through simple interventions. Eye Contact Lens 2014;40:225-31.

44 Cabana M, Rand C, Powe N, et al. Why don't physicians follow clinical practice guidelines? A framework for improvement. JAMA 1999;282:1458-65.

45 Hales C, Harpaz R, Ortega-Sanchez I, et al. Update on recommendations for use of herpes zoster vaccine. MMWR Morb Mortal Wkly Rep 2014;63:729-31. PMID: 25144544.

46 Centers for Disease Control and Prevention. Advisory Committee on Immunization Practices Summary Report. 2014. http://www.cdc.gov/vaccines/acip/meetings/ downloads/min-archive/min-jun13.pdf (accessed 8 Jan 2015).

47 Moore L, Remy V, Martin M, et al. A health economic model for evaluating a vaccine for the prevention of herpes zoster and post-herpetic neuralgia in the UK. Cost Eff Resour Alloc 2010;8:7.

48 Szucs TD, Pfeil AM. A systematic review of the cost effectiveness of herpes zoster vaccination. Pharmacoeconomics 2013;31:125-36.

49 Schmader K, Oxman M, Levin M, et al. Persistence of the efficacy of zoster vaccine in the shingles prevention study and the short-term persistence substudy. Clin Infect Dis 2012;55:1320-8.

50 Morrison VA, Johnson GR, Schmader KE, et al. Long-term persistence of zoster vaccine efficacy. Clin Infect Dis 2015;60:900-9.

51 Li X, Zhang JH, Betts RF, et al. Modeling the durability of ZOSTAVAX® vaccine efficacy in people $\geq 60$ years of age. Vaccine 2015;33:1499-505; pii: S0264-410X (14)01429-7.

52 Levin M, Schmader K, Zerbe G, et al. Safety, tolerability, and immunogenicity of a booster dose of zoster vaccine administered $\geq 10$ years after a first dose compared with a first dose of zoster vaccine. 20th IAGG World Congress of Gerontology and Geriatrics; 23-27 June 2013, Seoul. 
53 Yawn BP, Wollan PC, Kurland MJ, et al. Herpes zoster recurrences more frequent than previously reported. Mayo Clin Proc 2011;86:88-93.

54 Hoang-Xuan T, Büchi ER, Herbort $\mathrm{CP}$, et al. Oral acyclovir for herpes zoster ophthalmicus. Ophthalmology 1992;99:1062-70; discussion 1070-1. PMID: 1495785.

55 Cobo M, Foulks GN, Liesegang T, et al. Observations on the natural history of herpes zoster ophthalmicus. Curr Eye Res 1987;6:195-9.

56 Degreef H, Famciclovir Herpes Zoster Clinical Study Group. Famciclovir, a new oral antiherpes drug: results of the first controlled clinical study demonstrating its efficacy and safety in the treatment of uncomplicated herpes zoster in immunocompetent patients. Int J Antimicrob Agents 1994;4:241-6.

57 Tyring SK, Beutner KR, Tucker BA, et al. Antiviral therapy for herpes zoster: randomized, controlled clinical trial of valacyclovir and famciclovir therapy in immunocompetent patients 50 years and older. Arch Fam Med 2000;9:863-9.

58 Aggarwal S, Cavalcanti BM, Pavan-Langston D. Treatment of pseudodendrites in herpes zoster ophthalmicus with topical ganciclovir 0.15\% gel. Cornea 2014;33:109-13.

59 Sy A, McLeod SD, Cohen EJ, et al. Practice patterns and opinions in the management of recurrent or chronic herpes zoster ophthalmicus. Cornea 2012;31:786-90.

60 Miserocchi E, Fogliato G, Bianchi I, et al. Clinical features of ocular herpetic infection in an Italian referral center. Cornea 2014;33:565-70.

61 Pavan-Langston D, Yamamoto S, Dunkel EC. Delayed herpes zoster pseudodendrites. Polymerase chain reaction detection of viral DNA and a role for antiviral therapy. Arch Ophthalmol 1995;113:1381-5.

$62 \mathrm{Hu} A Y$, Strauss EC, Holland GN, et al. Late varicella-zoster virus dendriform keratitis in patients with histories of herpes zoster ophthalmicus. Am J Ophthalmol 2010;149:214-220.e3.

63 No authors listed. Acyclovir for the prevention of recurrent herpes simplex virus eye disease. Herpetic Eye Disease Study Group. N Engl J Med 1998;339:300-6.

64 Baratz $\mathrm{KH}$. The role of antiviral therapy after the resolution of acute herpes simplex keratitis or acute herpes zoster ophthalmicus. Arch Ophthalmol 2012;130:108-10.
65 Gilden D, Nagel MA, Mahalingam R, et al. Clinical and molecular aspects of varicella zoster virus infection. Future Neurol 2009;4:103-17.

66 Mahalingam R, Wellish M, Brucklier J, et al. Persistence of varicella-zoster virus DNA in elderly patients with postherpetic neuralgia. J Neurovirol 1995;1:130-3

67 Nagel MA, Forghani B, Mahalingam R, et al. The value of detecting anti-VZV IgG antibody in CSF to diagnose VZV vasculopathy. Neurology 2007;68:1069-73.

68 Nagel MA, Gilden D. Neurological complications of varicella zoster virus reactivation. Curr Opin Neurol 2014;27:356-60.

69 Takase H, Kubono R, Terada Y, et al. Comparison of the ocular characteristics of anterior uveitis caused by herpes simplex virus, varicella-zoster virus, and cytomegalovirus. Jpn J Ophthalmol 2014;58:473-82.

70 Nagel MA, Choe A, Cohrs RJ, et al. Persistence of varicella zoster virus DNA in saliva after herpes zoster. J Infect Dis 2011;204:820-4.

71 Birlea M, Cohrs RJ, Bos N, et al. Search for varicella zoster virus DNA in saliva of healthy individuals aged 20-59 years. J Med Virol 2014;86:360-2.

72 Nagel MA, Khmeleva N, Boyer PJ, et al. Varicella zoster virus in the temporal artery of a patient with giant cell arteritis. J Neuro/ Sci 2013;335:228-30.

73 Nagel MA, Bennett JL, Khmeleva N, et al. Multifocal VZV vasculopathy with temporal artery infection mimics giant cell arteritis. Neurology 2013;80:2017-21.

74 Gilden D, White T, Khmeleva N, et al. Prevalence and distribution of VZV in temporal arteries of patients with giant cell arteritis. Neurology Published Online First: 18 Feb 2015. doi:10.1212/WNL.0000000000001409

75 Nagel M, Gilden D. Editorial commentary: varicella zoster virus infection: generally benign in kids, bad in grown-ups. Clin Infect Dis 2014;58:1504-6.

76 Young RC, Hodge DO, Liesegang TJ, et al. Incidence, recurrence, and outcomes of herpes simplex virus eye disease in Olmsted County, Minnesota, 1976-2007: the effect of oral antiviral prophylaxis. Arch Ophthalmol 2010;128:1178-83.

77 Gnann JW Jr. Antiviral therapy of varicella-zoster virus infections. In: Arvin A, Campadelli-Fiume G, Mocarski E, et al. Human Herpesviruses: Biology, Therapy, and Immunoprophylaxis. Cambridge: Cambridge University Press, 2007. Chapter 65. PMID: 21348091. http:///www.ncbi.nlm.nih.gov/books/NBK47401 